\title{
A study of stress-induced phase transformation and \\ micromechanical behavior of CuZr-based alloy by in-situ neutron diffraction
}

Dongmei Wang ${ }^{\text {a, b, c, Juan Mu }}{ }^{\text {a, }}$, Yan Chen ${ }^{\text {b }, ~ Y u m i n g ~ Q i ~}{ }^{\text {b }}$, Wei Wu ${ }^{\text {b }}$, Yandong Wang a , Haijian Xu ${ }^{\text {a }}$, Haifeng Zhang ${ }^{d}$, Ke An ${ }^{b, *}$

\begin{abstract}
The stress-induced phase transformation and micromechanical behavior of CuZr-based alloy were investigated by in-situ neutron diffraction. The pseudoelastic behavior with a pronounced strain-hardening effect is observed. The retained martensite nuclei and the residual stress obtained from the $1^{\text {st }}$ cycle reduce the stress threshold for the martensitic transformation. A
\end{abstract}


critical stress level is required for the reverse martensitic transformation from martensite to B2 phase. An increase of intensity for the B2 (110) plane in the $1^{\text {st }}$ cycle is caused by the twinning along the $\{112\}<111>$ twinning system. The convoluted stress partitioning influenced by the elastic and transformation anisotropy along with the newly formed martensite determines the microstress partitioning of the studied CuZr-based alloy. The reversible martensitic transformation is responsible for the pseudoelasticity. The macro mechanical behavior of the pure B2 phase can be divided into 3 stages, which are mediated by the evolvement of the martensitic transformation.

This manuscript has been authored by UT-Battelle, LLC under Contract No. DE-ACO500OR22725 with the U.S. Department of Energy. The United States Government retains and the publisher, by accepting the article for publication, acknowledges that the United States Government retains a non-exclusive, paid-up, irrevocable, world-wide license to publish or reproduce the published form of this manuscript, or allow others to do so, for United States Government purposes. The Department of Energy will provide public access to these results of federally sponsored research in accordance with the DOE Public Access Plan (http://energy.gov/downloads/doe-public-access-plan).

Keywords: In-situ neutron diffraction technique; Macro mechanical behavior; Stress-induced martensitic transformation; Micromechanical behavior; Stress partitioning

\section{Introduction}

The poor plasticity of conventional Bulk Metallic Glasses (BMGs) due to the highly localized shear bands has limited their engineering applications [1-6], although BMGs are one of the potential candidates for engineering structural materials due to their high strength, high hardness, and high wear resistance etc [7-12]. Recent efforts showed the poor plasticity could be adjusted 
by introducing crystalline phases into the glass matrix, i.e. Bulk Metallic Glass Composites (BMGCs). The composites can possess the plastic deformability [13-41] up to about the total $22 \%$ compressive strain [19]. However, to accommodate plastic strain, a series of ZrTi-based and Tibased composites show the obvious work softening after yielding, which restrict their practical engineering applications [16,20-21]. In contrast, excellent work hardening has been achieved in the CuZr-based BMGCs [22-41]. As a result, the CuZr-based BMGCs containing B2 crystallites have garnered much interest owing to their outstanding work hardening ability.

Recently, efforts have been taken to explain the mechanical behavior of the B2 crystalline in the CuZr-based BMGCs by ex-situ characterization methods, including X-ray diffraction (XRD), scanning electron microscope (SEM), transmission electron microscope (TEM), etc. For example, for the nano-sized B2 CuZr crystals, the precipitation $[6,22,24,28,33]$ as well as the twinning of these nanocrystals [6] provides an effective way to counteract the strain softening. For the microsized B2 CuZr crystals, Pauly and Eckert [30-31] believe the compatibility of the elastic properties of the $\mathrm{B} 2$ phase and the amorphous matrix promotes the slip to transfer from the amorphous matrix to the $\mathrm{B} 2$ phase. Moreover, the B2 phase in BMGCs upon loading can also undergo martensitic transformation from a cubic primitive structure to a monoclinic structure similar in the CuZr-based shape memory alloys [42-43], and then cause the stress concentration along the reinforced B2 phase and amorphous matrix interfaces, which facilitates the multiplication and mutual interaction of the shear bands to avoid catastrophic fracture $[27,31,35$ $36,38-41]$

From the summary above, it can be seen the relative behavior of B2 phase upon loading is bound up with the excellent mechanical properties of CuZr-based BMGCs. The occurrence of the martensitic transformation of the B2 phase in CuZr-based alloys has been demonstrated 
qualitatively under stress up to approximately $-1100 \mathrm{MPa}$ by in-situ high-energy X-ray diffraction [30,44]. However, the detailed micromechanical behaviors of the B2 phase and martensitic transformation and their effects on the macroscopic properties were not revealed in the previous reports. Considering the importance of the B2 deformation behavior in the understanding of the plasticity improvement and work hardening behavior of BMCGs, it is necessary to determine its micromechanical properties during the phase transformation. Besides, the stress-induced martensitic transformation is reversible upon unloading, which makes post observation measurements less than ideal for understanding the stress related behavior. In situ techniques are the key to unravel the reversible phase transformation. Howbeit the reports even on the composites by in-situ SEM or TEM characterization are scarce. Compared with the other in situ techniques, in situ neutron diffraction technique is superior for this purpose because the accurate measurement of the relationship between the lattice strain and stress as well as the phase transformation of a large bulk volume, which is considered as one of the most direct and effective methods to study the deformation mechanism of materials, such as engineering materials, shape memory alloys and composites [45-52]. At the VULCAN engineering materials diffractometer [53], Spallation Neutron Source (SNS), Oak Ridge National Laboratory (ORNL), the high flux, high resolution and deep penetration of neutrons enables the in situ study of bulk materials [54-55]. In this study, in situ neutron diffraction method was carried out to explicitly study the martensitic transformation and the micromechanical behavior of the B2 phase with the evolution of the phase transformation. 


\section{Experimental}

\subsection{Synthesis of the CuZr-based alloy}

$\mathrm{Cu}_{36.45} \mathrm{Zr}_{49.5} \mathrm{Al}_{9} \mathrm{Ni}_{4.05} \mathrm{Nb}_{1}$ (atom \%) ingots were synthesized by arc melting a mixture of the constituent elements in a Ti-getter high-purity argon atmosphere. The $\mathrm{Ni}_{80.2} \mathrm{Nb}_{19.8}$ master alloy was initially prepared because of the higher melting point of $\mathrm{Nb}$ and then melted with the remaining elements. To ensure chemical homogeneity, each ingot was melted repetitively at least four times. The rods with $8 \mathrm{~mm}$ in diameter were produced via the copper mold injection casting method. The cylindrical specimens with a diameter of $6 \mathrm{~mm}$ and a length of $12 \mathrm{~mm}$ were machined for in-situ loading experiments.

\subsection{In situ neutron diffraction experiments}

The specimen was mounted horizontally in the VULCAN loadframe with the axial direction parallel to the loading direction (LD), as shown in Fig. 1. The specimen was first uniaxially precompressed to the stress of $\sim-215 \mathrm{MPa}$ in order to eliminate the sluggish gaps between the sample and the grips and then unloaded to $0 \mathrm{MPa}$ followed by two compressive loadingunloading cycles with a different peak stress for each cycle about -941 MPa and -1220 MPa in order to observe the martensite phase change reversibility and understand the effect of the further deformation on the recovery ability, respectively. Under the displacement control, the strain rates were approximately $2.3 \sim 2.8 \times 10^{-6} \mathrm{~s}^{-1}$. In situ neutron diffraction measurement was performed continuously throughout the loading and unloading processes. Since the angle between the incident neutron beam and the sample loading axis is $45^{\circ}$, two diffraction patterns in the axial and radial directions with diffraction vectors parallel and perpendicular to the applied load could be recorded simultaneously by using the two neutron detectors at two fixed angular positions $2 \theta$ $= \pm 90^{\circ}$. The neutron incident beam size was confined as $4 \mathrm{~mm}$ in horizontal and $5 \mathrm{~mm}$ in vertical, 
and the receiving collimators were $5 \mathrm{~mm}$, resulting in $\sim 100 \mathrm{~mm}^{3}$ neutron gauge volume. Considering the nominal grain size of $200-300 \mathrm{~nm}$ [56], the neutron gauge volume with tens of thousands of grains is adequate for the bulk averaging measurement by diffraction experiments. The collected neutron diffraction data were chopped with 5-minute interval based on the quality of the diffraction profiles and then analyzed by single peak fitting using the VDRIVE software [57]. Lebail refinement in GSAS [58] was used to analyze the phase evolution before and after deformation.

The deformation mechanism of the studied alloy was analyzed by the lattice strain (peak positions), full widths at half maximum (FWHM-peak widths) and normalized intensities of the B2 and martensite phases obtained from the measured diffraction patterns $[45,53,59-63]$. The lattice strain $\varepsilon_{h k l}$ for the different $\{h k l\}$ lattice planes of the studied phases was calculated by Eq. (1):

$\varepsilon_{h k l}=\left(d_{h k l}-d_{0, h k l}\right) / d_{0, h k l}$

where $d_{h k l}$ is the lattice spacing and $d_{0, h k l}$ is the lattice spacing under stress-free state [18,59-63]. However, it's difficult to determine the absolute stress-free $d_{0, h k l}$ value of the martensite because of its emergence while the sample was under loading. The relative lattice strain of the martensite was obtained by referring to the d-spacing of the (020) B19' peak which can be detected at early emergence.

The integrated intensities of the B2 phase among the specifically oriented austenite grain families were normalized with respect to the integrated intensity under zero stress e.g. $I_{h k l} I_{0, h k l}$, where $I_{h k l}$ and $I_{0, h k l}$ are the integrated intensities of the different B2 lattice planes under the compressive load and zero load, respectively [59-61]. The normalized integrated intensities in 
the equally oriented $h k l$ austenite or martensite grain families of the austenite or martensite phase scale with the volume fraction variation of the B2 or martensite phase [60]. The microstress $\sigma_{h k l}$ evolution in the different lattice planes for the both phases were obtained by Eq. (2) [18]:

$\sigma_{h k l}=E_{h k l} \cdot \varepsilon_{h k l}$

where $E_{h k l}$ is the elastic diffraction constant and $\varepsilon_{h k l}$ is the lattice strain for the different $(h k l)$ lattice planes.

\section{Results and discussions}

\subsection{Mechanical behavior}

The mechanical behavior of the studied alloy is studied through the compression experiment. The measured mechanical compressive stress-strain curve is shown in Fig. 2 for the two loadingunloading cycles. The stress-strain curve deviates clearly from the initial linearity at the stress level of -298 $\mathrm{MPa}$ in the $1^{\text {st }}$ cycle while there is a 'double-yielding' behavior at the stress of $183 \mathrm{MPa}$ and $\sim-941 \mathrm{MPa}$ in the $2^{\text {nd }}$ cycle [38]. The stress for the $2^{\text {nd }}$ cycle is lower than the $1^{\text {st }}$ cycle under the same strain condition, but the difference between the $1^{\text {st }}$ and $2^{\text {nd }}$ cycle gradually decreases to the $0 \mathrm{MPa}$ at the maximum stress $(\sim-941 \mathrm{MPa})$ of the $1^{\text {st }}$ cycle. The pronounced strain-hardening behavior was observed in this studied alloy for the both compressive loading cycles. This is similar to the compressive mechanical curves for the other CuZr-based shape memory alloys with different compositions [65]. There is an obvious pseudoelastic behavior where the total strain is up to $-6.8 \%$ beyond the $2 \%$ elastic strain limit. This behavior was observed in most of the shape memory alloys [59-64]. After unloading in the $2^{\text {nd }}$ cycle, the residual strain increases from $\sim-1.4 \%$ (in the $1^{\text {st }}$ cycle) to $\sim-3.3 \%$. 


\subsection{In situ characterization of the phase transformation}

To understand the macro mechanical behavior, the structural evolution of the current alloy during the deformation was studied by in situ neutron diffraction. The diffraction pattern along with the Lebail refinement fitting demonstrates that the as-cast sample consists of the pure B2 phase (pm-3m space group \# 221), as shown in Fig. 3(a). Fig. 3(c) and (d) display the twodimensional (2-D) and three-dimensional (3-D) plots regarding the variations of the diffraction spectra throughout the loading and unloading cycles in the loading direction. When the applied compressive stress reaches about $-298 \mathrm{MPa}$ in the $1^{\text {st }}$ cycle, a new Bragg peak appears, which is indexed as the (020) reflection of the B19' martensite $\left(P 2_{l} / m\right.$ space group \# 10$)$ with a d-spacing of $\sim 2.065 \AA$ [Fig. 3(c) and (d)]. With the increase of compressive stress, the intensities of the new phase increase accompanied by the decrease of the $\mathrm{B} 2$ phase and more new Bragg peaks belonging to the superstructure martensite ( $\mathrm{Cm}$ space group \# 12) and the B19' base martensite $\left(P 2_{1} / m\right.$ space group \# 10) appear [Fig. 3(b)][66]. A large number of martensite peaks overlap not only with each other but also with some peaks of the B2 phase due to the low symmetry of monoclinic structure of the martensite [Fig. 3(b)][64]. Single peak analysis was performed for peaks not overlapping significantly for each of the two phases. Especially for the B2 phase, the (200) peak overlaps badly with the martensite peaks. Besides, the peak intensity of the (222) peak is not strong enough during the phase transformation to provide solid quantitative information [Fig. 3(a) and (b)]. Thus, these two peaks were not considered during the analysis of the lattice strain, peak widths and intensities. The austenite did not completely transform to the martensite as austenite peaks did not fully vanish at the peak stress ( -1220 MPa, -6.8 \% strain) in the $2^{\text {nd }}$ cycle [Fig. 3(c) and (d)]. 


\subsection{Martensitic transformation}

The intensity evolution of each phase as a function of applied stress or strain gives the information about the relationship between the phase transformation and the macro mechanical properties. Fig. 4 shows the normalized integrated intensities variations for the selected B2 $(h k l)$ and the B19' (020) grain families in the loading direction, respectively.

In the $1^{\text {st }}$ cycle, the martensitic transformation takes place at the stress of $\sim-298 \mathrm{MPa}$ [Fig. 4(e)]. Accordingly, the relative integrated intensities of some of the B2 lattice planes start to show the decrease trend [Fig. 4(a) and (c)]. The further the martensite intensity increases, the more the intensities of the B2 lattice planes decrease. However, the observed starting points of the intensities decrease for the different B2 lattice planes are different, which the B2 (310) lattice plane starts decreasing last. This is mainly attributed to the interaction of the elastic anisotropy of the differently oriented B2 grain families and transformation anisotropy associated with the martensitic transformation [61]. After unloading, the intensity of the martensite peak does not start reducing until the stress decreases to $-735 \mathrm{MPa}$ [Fig. 4(e)]. After the completely removal of the applied stress, the martensite phase does not fully vanish and hence turns into the retained martensite.

In the $2^{\text {nd }}$ cycle, the martensitic transformation occurs at the stress of -183 MPa, which is lower than that in the $1^{\text {st }}$ cycle [Fig. 4(e)]. This indicates a reduction of the phase transformation stress threshold. It was suggested that this is due to the retained martensite nuclei [63] and residual stress [61] obtained from the $1^{\text {st }}$ cycle. With the proceeding of the martensitic transformation, the almost linear decrease of the normalized integrated intensities for the B2 phase are observed in the $1^{\text {st }}$ and $2^{\text {nd }}$ cycles until the peak stress of the $1^{\text {st }}$ cycle $(-941 \mathrm{MPa})$. However, the B2 (211) plane in the $2^{\text {nd }}$ cycle decreases slowly at the stress of $\sim-1037 \mathrm{MPa}$ and 
almost reaches a plateau at the stress level of -1171 MPa [Fig. 4(b) and (d)]. This agrees with the intensity evolution of the B19' (020) grain families which saturates at the same level [Fig. 4(e) and (f)]. The intensity growth of the B2 (211) plane matches with the reduction of the B19' (020) grains.

During the unloading process, the intensity of the martensite peak in the $2^{\text {nd }}$ cycle starts to decrease at the similar stress level in the $1^{\text {st }}$ cycle ( -735 MPa) [Fig. 4(e)]. This indicates similar stress levels for the onset of the reverse martensitic transformation are observed for both cycles, which signifies that the reverse transformation from martensite to B2 phase does not start until a critical stress level is reached. Compared with the $1^{\text {st }}$ cycle, more retained martensite remains with the increase of the applied stress or strain in the $2^{\text {nd }}$ cycle.

The almost linear change relationship between the intensities evolution and the strain for both phases demonstrates the pseudoelasticity is mainly accommodated by the reversible martensitic transformation [Fig. 4(c), (d) and (f)].

It is worth noting before the martensitic transformation, a non-negligible increase of intensity for the B2 (110) plane is observed in the $1^{\text {st }}$ cycle but not in the $2^{\text {nd }}$ cycle. Considering the notable magnitude of the intensity increment but the little variations of FWHM [Fig. 5(c)] (which is sensitive to the lattice defects such dislocations densities) before the martensitic transformation in the $1^{\text {st }}$ cycle, this is presumably caused by the twinning which shows strong changes of reflection intensities but little disruption of lattice ordering. The $\{112\}<111>$ system is a well-known twinning system in the bcc structures which has 12 variants [67]. Here, the B2 phase shows the bcc structure instead of the cubic primitive structure in the current study due to the similar scattering factors for the $\mathrm{Cu}$ and $\mathrm{Zr}$ elements in the neutron diffraction experiments 
[Fig. 3(a)]. Thus, the twinning along the $\{112\}<111>$ twinning system could cause more $\{110\}$ planes to be detected if the angle between the $\{110\}$ plane and the loading direction is smaller than the $11.5^{\circ}$ (detector coverage angle) after twinning. When the phase transformation nucleates, the B2 (110) intensity starts to decrease with other planes. The peak increase does not show in the $2^{\text {nd }}$ cycle because the occurrence of the martensitic transformation lowers the stress threshold (the observed initial martensitic transformation stress reduced from -298 MPa in the $1^{\text {st }}$ cycle to $183 \mathrm{MPa}$ in the $2^{\text {nd }}$ cycle caused by the retained martensite nuclei and the residual stress as discussed before) before the twinning.

\subsection{Responses of the lattice strain and FWHM to the applied stress}

The micromechanical behavior for the $1^{\text {st }}$ and $2^{\text {nd }}$ cycles can be revealed by the evolutions of the lattice strain and FWHM, as depicted in Fig. 5.

In the $1^{\text {st }}$ cycle, before the appearance of the martensite phase where the stress level is below -298 MPa, the B2 phase exhibits an elastic anisotropic behavior where the elastic diffraction constants $E_{h k l}$ are different $[45,61-62,68]$ [Fig. 5(a)]. The $E_{h k l}$ calculated from the lattice strain correspondences to the applied stress as a linear function of the orientation parameter $A_{h k l}$ is shown in Fig. 6, and the parameter $A_{h k l}$ is given in Eq. (3) in terms of the Miller indices [45]:

$A_{h k l}=\left(h^{2} k^{2}+k^{2} l^{2}+l^{2} h^{2}\right) /\left(h^{2}+k^{2}+l^{2}\right)^{2}$

The fitted linear relationship describes that the reciprocal Young's modulus is given by: $1 / E_{h k l}$ $=S_{11}-2 S_{0} \cdot A_{h k l}$, where $S_{11}$ and $S_{0}$ are, $-0.01576,0.00776$, respectively. For cubic crystals that $S_{11}$, $S_{12}$ and $S_{44}$ are the compliance tensor $S$ components and $S_{0}=\left[S_{11}-S_{12}-1 / 2 \cdot S_{44}\right]$. Other $E_{h k l}$ of this kind of materials can be interpolated by this formula. With the given lattice strain, microstress on different planes will be obtained using Eq. (2) and discussed in the next chapter. 
As soon as the phase transformation starts, the slopes for the (110), (211) and (321) planes increase while the slope of (310) plane decreases, which is a result of internal stress redistribution among the different oriented $(h k l)$ grain families $[45,68-69,70]$. The stress partition of the newly formed martensite also impacts the micromechanical behavior of the B2 phase. One can see that the degree of the deviation from initial linearity for the multiple $(h k l)$ planes becomes larger with the progression of the martensitic transformation. This means the intergranular stress among particularly oriented $(h k l)$ B2 grain families becomes more profound with the increase of the stress level. This kind of intergranular stress assists the plastic deformation of the two phases [70].

For the B19' (020) grains, the relationship between the relative lattice strain and the stress starts to respond linearly at beginning in the $1^{\text {st }}$ cycle. The stress that the B19' (020) grains bears is proportional to the applied stress. However, with the increased accumulation of the martensite phase, the relative lattice strain of the B19' (020) grains start to respond nonlinearly at the stress of -821 MPa [Fig. 5(e)]. At the same time the FWHM variations show increasing change [Fig. 5(f)]. Since the FWHM variations are related to the generation of dislocations and the building up of intergranular stresses $[45,60]$, this along with the increasing slope of the relative lattice strain curve signifies that the plastic deformation of the B19' (020) grains occurs with the increase of the applied stress and the amount of the martensite phase. The B2 phase also shows the plastic deformation indicated by the change of its FWHM which shows an increasing trend during the deformation but could not recover to the initial state after the complete unloading [Fig. $5(\mathrm{c})]$.

In the $2^{\text {nd }}$ cycle, a linearity of the lattice strain vs. applied stress up to $-183 \mathrm{MPa}$ is also observed before the rise of the martensite which is lower than the $1^{\text {st }}$ cycle [Fig. 5(b)]. This 
consists with the critical stress required for the martensitic transformation in the $1^{\text {st }}$ and $2^{\text {nd }}$ cycles (chapter 3.3). The micromechanical behaviors of the $\mathrm{B} 2$ phase in the $2^{\text {nd }}$ cycle are analogous to the ones in the $1^{\text {st }}$ cycle before the peak stress of the $1^{\text {st }}$ cycle. However, when the applied stress beyond the stress maxima of the $1^{\text {st }}$ cycle and increases to $\sim 1037 \mathrm{MPa}$, the slope of the (211) plane decreases accompanied by the slight increase of the (310) and (321) planes, especially for the compliant (310) plane, which bears more stress during the previous deformation stage as a result of increased load sharing of the increasing martensite as shown in Fig. 5(b) and (e). At the same time, the FWHM shows an accelerated increase at the stress of $1037 \mathrm{MPa}$ and a more conspicuous increase at the stress of $-1171 \mathrm{MPa}$ [Fig. 5(d)]. After unloading, the residual intergranular strain are observed for all the B2 $(h k l)$ lattice planes, while they become larger with the increase of stress maxima in each cycle, especially for the (310) plane [Fig. 5(a) and (b)].

As for the B19' (020) grains in the $2^{\text {nd }}$ cycle, the deviation of the relative lattice strain curves appears at the stress of $\sim-500 \mathrm{MPa}$ and meanwhile the FWHM starts to increase [Fig. 5(e) and (f)]. According to the analysis of the $1^{\text {st }}$ cycle, this is a result of the plastic deformation of the B19', which occurred at a lower applied stress level compared to the $1^{\text {st }}$ cycle ( -821 MPa). At the stress of -1037 MPa, it can be seen the slope of the relative lattice strain curves shows a decrease trend and the FWHM starts to increase greatly. A more obvious change for the relative lattice strain and FWHM can be observed at the stress of -1171 MPa.

Based on the chapter 3.3, the stress of -1037 and $-1171 \mathrm{MPa}$ are consistent with the slow progression and the saturation of the martensitic transformation. Combined with the variations of the lattice strain and FWHM for the B2 and martensite phases at the stress of -1037 and -1171 $\mathrm{MPa}$, respectively, it can be concluded that the progression of the martensitic transformation 
affects the stress partitioning, and eventually during this stage the plasticity is mainly dominated by the dislocations movement instead of the martensitic transformation. Although only one typical $(h k l)$ of the B19' phase is shown here, the evidence of stress partitioning due to the convoluted intergranular stress and phase transformation can be observed from the in-situ measurement.

Although the reverse phase transformation evolves, the response of the lattice strain of B19' (020) grains during the loading and unloading overlaps almost completely in the $1^{\text {st }}$ and $2^{\text {nd }}$ cycles, and does not show a markedly different residual lattice strain for the two cycles [Fig. 5(e)]. This indicates the deformation behavior of the B19' (020) grains are coincidentally independent of the volume fraction. Taking this feature, the overlapped linear unloading part before the onset of the reverse transformation ( -735 MPa) can be used for calculating the 'pseudoelastic diffraction constant' for the B19' (020) plane, which was about $124 \mathrm{GPa}$. This value will be used for calculating the B19' (020) microstress in the following discussion.

\subsection{The microstress evolution of the studied CuZr-based alloy}

Based on the analysis of characteristics revealed by phase transformation, lattice strain and FWHM, the microstress evolution of the studied CuZr-based alloy can be revealed and its correlation to the macroscopic behavior can be found. The microstress evolution of selected ( $h k l)$ planes of the phases vs. strain can be derived by multiplying the lattice strain and the corresponding elastic diffraction constants (Eq. 2). For clarity, the results without the first unloading segment and second loading below the peak stress of the first cycle are depicted in Fig. 7. Results for all the measured responses can be found in the supplementary A (Fig. A.1). The corresponding macroscopic mechanical curve (Fig. 2) is replotted in Fig. 7. It should be noticed that the lattice strain calculation method of the stress induced martensite phase (chapter 2.2) is 
different from the $\mathrm{B} 2$ phase due to the missing of the absolute stress-free d-spacing. Therefore, the absolute microstress for B19' (020) grains cannot be given but the changes from the first measurable emergence.

It is clear that the macro mechanical behavior can be correlated to the micro deformation behavior of the involved $h k l s$ in both phases from the Fig. 7. The deformation of the studied CuZr-based alloy can be divided into 3 stages: stage $1(<298 \mathrm{MPa})$, stage $2(298-1037 \mathrm{MPa})$ and stage $3(>1037 \mathrm{MPa})$. In the stage 1, i.e. before the martensitic transformation ( -298 MPa), the different B2 $(h k l)$ planes behave elastically. During this stage, the B2 phase is found to deform mainly by twinning (chapter 3.3). A relative lower stress (-298 $\mathrm{MPa})$ is required for inducing the martensitic transformation and the studied alloy commences the stage 2 deformation. Accordingly, the deviations for different B2 $(h k l)$ planes start. With the proceeding of martensitic transformation, the discrepancies of microstress increase for the measured B2 grain families as well as the B19' (020) grains, indicating a dynamic stress partitioning due to the elastic and transformation anisotropy [61]. When the applied stress achieves -941 MPa of the maximum of the $1^{\text {st }}$ cycle, the depletion of the residual stress obtained from the $1^{\text {st }}$ cycle induces the additional intergranular stress in both phases due to the higher applied stress, which accounts for the second 'yield point' in the $2^{\text {nd }}$ cycle. The microstress for B2 and B19' phases constantly increase with the proceeding of the martensitic transformation and the deformation until the stress of - $1037 \mathrm{MPa}$. The bulk deformation of the stage 2 is primarily dictated by the martensitic transformation. When the stress is beyond -1037 MPa (stage 3), as a result of the slow progression of the martensitic transformation, the slopes of the microstress curves for the B2 (211) plane and B19' (020) plane increase while the ones for the B2 (310) and (321) planes decrease, which becomes more obvious at the stress of $\sim-1171 \mathrm{MPa}$, i.e. the martensitic transformation saturates. This 
eventually leads to the decreasing work hardening rate. During this stage, the studied alloy mainly proceeds with the plastic deformation which is primarily dominated by the dislocation movement (chapter 3.4).

Upon unloading, due to the reverse phase transformation, the strain recovers, but not fully due to the irreversible dislocations and retained martensite as a result of higher applied stress and higher residual stresses developed in both phases, respectively [60]. The microstress partitioning is a convolution of the elastic and transformation anisotropy as well as the dynamic interphase balancing, and as a result, different residual stresses for both phases were developed.

The above summary of the 3 stages deformation characteristics of the pure B2 phase will aid the understanding of the CuZr-based BMGCs with the $\mathrm{B} 2$ phase. The 3 deformation stages for the B2 phase depend on the preparation of the CuZr-based BMGCs with different fractions of the amorphous and B2 phases. Clearly, the more B2 phase exists, the more possibly all the 3 stages could happen during the BMGCs' deformation. Accordingly, the work hardening behavior and plasticity are more pronounced for the composites although the strength may reduce [38].

\section{Summary}

The stress-induced phase transformation and micromechanical behavior of CuZr-based alloy were investigated by in-situ neutron diffraction. A non-negligible increase of intensity for the B2 (110) plane is observed in the $1^{\text {st }}$ cycle due to the twinning along the $\{112\}<111>$ twinning system. The plastic deformation dominates the macro mechanical behavior by dislocation movements, when the martensitic transformation gradually saturates. The reversible martensitic transformation is responsible for the pseudoelasticity. The mechanical behaviors of the CuZrbased alloy containing the pure B2 phase show 3-stage deformation characteristics. 


\section{Acknowledgements}

In situ neutron diffraction experiments were carried out at SNS, ORNL, supported by the U.S. Department of Energy, Basic Energy Sciences, Scientific User Facilities Division. Dongmei Wang is grateful for the financial support provided by the China Scholarship Council (CSC) during the visit to the Oak Ridge National Laboratory (ORNL) and the University of Tennessee. Y.D. Wang, J. Mu and D.M. Wang acknowledge the financial support from the National Natural Science Foundation of China (NSFC) (Grant No.s 51231002, 51471032 and 51527801 and 51301034). The authors thank Mr. M. Frost, Mr. H. Skorpenske from ORNL and Dr. Z.W. Zhu, Dr. Z.K. Li, Dr. P.F. Sha, Mr. Y. Liu, Mr. W.Q. Liu, Mr. D.M. Liu and Mr. D.C. Yu from Shenyang Chinese Academy of Sciences for their technical assistance in this research.

\section{References}

[1] C.A. Pampillo, Flow and fracture in amorphous alloys, J. Mater. Sci. 10 (1975) 1194-1227.

[2] F. Spaepen, A microscopic mechanism for steady state inhomogeneous flow in metallic glasses, Acta Metall. 25 (1977) 407-415.

[3] Z.F. Zhang, J. Eckert, L. Schultz, Difference in compressive and tensile fracture mechanisms of $\mathrm{Zr}_{59} \mathrm{Cu}_{20} \mathrm{Al}_{10} \mathrm{Ni}_{8} \mathrm{Ti}_{3}$ bulk metallic glass, Acta Mater. 51 (2003) 1167-1179.

[4] F.F. Wu, Z.F. Zhang, S.X. Mao, A. Peker, J. Eckert, Effect of annealing on the mechanical properties and fracture mechanisms of a $\mathrm{Zr}_{56.2} \mathrm{Ti}_{13.8} \mathrm{Nb}_{5.0} \mathrm{Cu}_{6.9} \mathrm{Ni}_{5.6} \mathrm{Be}_{12.5}$ bulk-metallic-glass composite, Phys. Rev. B 75 (2007) 134201.

[5] Y.F. Sun, C.H. Shek, F.S. Li, S.K. Guan, Stress-induced martensitic transformations in CuZrAl bulk metallic glass forming alloys, Mat. Sci. Eng. A 479 (2008) 31-36.

[6] S. Pauly, S. Gorantla, G. Wang, U. Kühn, J. Ecker, Transformation-mediated ductility in CuZr-based bulk metallic glasses, Nat. Mater. 9 (2010) 473-477. 
[7] A. Inoue, Stabilization of metallic supercooled liquid and bulk amorphous alloys, Acta Mater. 48 (2000) 279-306.

[8] W.H. Wang, C. Dong, C.H. Shek, Bulk metallic glasses, Mater. Sci. Eng. R 44 (2004) 45-89.

[9] M.F. Ashby, A.L. Greer, Metallic glasses as structural materials, Scripta Mater. 54 (2006) 321-326.

[10] C. Schuh, T. Hufnagel. T.U. Ramamurty, Mechanical behavior of amorphous alloys, Acta Mater. 55 (2007) 4067-4109.

[11] L.C. Zhang, F. Jiang, D.H. Zhang, L. H, J. Sun, J.T. Fan, Z.F. Zhang, In-Situ precipitated nanocrystal beneficial to enhanced plasticity of $\mathrm{Cu}-\mathrm{Zr}$ based bulk metallic glasses, Adv. Eng. Mater. 10 (2008) 943950.

[12] J.W. Qiao, Y. Zhang, P.K. Liaw, G.L. Chen, Micromechanisms of plastic deformation of a dendrite/Zr-based bulk-metallic-glass composite, Scripta Mater. 61 (2009) 1087-1090.

[13] A. Leonhard, L.Q. Xing, M. Heilmaier, A. Gebert, J. Eckert, and L. Schultz, Effect of crystalline precipitations on the mechanical behavior of bulk glass forming Zr-based alloys, Nanostruct. Mater. 10 (1998) 805-817.

[14] C.C. Hays, C.P. Kim, W.L. Johnson, Microstructure controlled shear band pattern formation and enhanced plasticity of bulk metallic glasses containing in situ formed ductile phase dendrite dispersions, Phys. Rev. Lett. 84 (2000) 2901-2904.

[15] Y.C. Kim, J.H. Na, J.M. Park, D.H. Kim, J.K. Lee, W.T. Kim, Role of nanometer-scale quasicrystals in improving the mechanical behavior of Ti-based bulk metallic glasses, Appl. Phys. Lett. 83 (2003) 3093-3095.

[16] D.C. Hofmann, J.Y. Suh, A. Wiest, G. Duan, M. L. Lind, M.D. Demetriou, W.L. Johnson, Designing metallic glass matrix composites with high toughness and tensile ductility, Nature 451 (2008) 1085-1089. [17] D.C. Hofmann, J.Y. Suh, A. Wiest, W. Johnson, New processing possibilities for highly toughened metallic glass matrix composites with tensile ductility, Scripta Mater. 59 (2008) 684-687. 
[18] J. Mu, Z.W. Zhu, R. Su, Y.D. Wang, H.F. Zhang, Y. Ren, In situ high-energy X-ray diffraction studies of deformation-induced phase transformation in Ti-based amorphous alloy composites containing ductile dendrites, Acta Mater. 61 (2013) 5008-5017.

[19] Y. Wu, H. Wang, X.J. Liu, X.H. Chen, X.D. Hui, Y. Zhang, Z.P. Lu, Designing bulk metallic glass composites with enhanced formability and plasticity, J. Mater. Sci. Technol. 30 (2014) 566-575.

[20] J.W. Qiao, A.C. Sun, E.W. Huang, Y. Zhang, P.K. Liaw, C.P. Chuang, Tensile deformation micromechanisms for bulk metallic glass matrix composites: From work-hardening to softening, Acta Mater. 59 (2011) 4126-4137.

[21] J.W. Qiao, Y. Zhang, H.L. Jia, H.J. Yang, P.K. Liaw, B.S. Xu, Tensile softening of metallic-glassmatrix composites in the supercooled liquid region, Appl. Phys. Lett. 100 (2012) 121902.

[22] A. Inoue, W. Zhang, T. Tsurui, A.R. Yavari, A.L. Greer, Unusual room-temperature compressive plasticity in nanocrystal toughened bulk copper-zirconium glass, Philos. Mag. Lett. 85 (2005) 221-229.

[23] Y.F. Sun, B.C. Wei, Y.R. Wang, W.H. Li, T.L. Cheung, C.H. Shek, Plasticity-improved Zr-Cu-Al bulk metallic glass matrix composites containing martensite phase, Appl. Phys. Lett. 87 (2005) 051905.

[24] K.B. Kim, J. Das, F. Baier, M.B. Tang, W.H. Wang, J. Eckert, Heterogeneity of a $\mathrm{Cu}_{47.5} \mathrm{Zr}_{47.5} \mathrm{Al}_{5}$ bulk metallic glass, Appl. Phys. Lett. 88 (2006) 051911.

[25] F. Jiang, D.H. Zhang, L.C. Zhang, Z.B. Zhang, L. He, J. Sun, Z.F. Zhang, Microstructure evolution and mechanical properties of $\mathrm{Cu}_{46} \mathrm{Zr}_{47} \mathrm{Al}_{7}$ bulk metallic glass composite containing CuZr crystallizing phases, Mater. Sci. Eng. A 467 (2007) 139-145.

[26] S. Pauly, J. Das, C. Duhamel, J. Eckert, Martensite formation in a ductile $\mathrm{Cu}_{47.5} \mathrm{Zr}_{47.5} \mathrm{Al}_{5}$ bulk metallic glass composite, Adv. Eng. Mater. 9 (2007) 487-491.

[27] S. Pauly, J. Das, C. Duhamel, J. Eckert, Effect of titanium on microstructure and mechanical properties of $\mathrm{Cu}_{50} \mathrm{Zr}_{50-\mathrm{x}} \mathrm{Ti}_{\mathrm{x}}(2.5 \leq \mathrm{x} \leq 7.5)$ glass matrix composites, Metall. Mater. Trans. A 39 (2007) 18681873. 
[28] L. Zhang, F. Jiang, D. Zhang, L. He, J. Sun, J. Fan, Z.F. Zhang, In-Situ precipitated nanocrystal beneficial to enhanced plasticity of $\mathrm{Cu}-\mathrm{Zr}$ based bulk metallic glasses, Adv. Eng. Mater. 10 (2008) 943950.

[29] S. Pauly, J. Das, J. Bednarcik, N. Mattern, K.B. Kim, D.H. Kim, J. Eckert, Deformation-induced martensitic transformation in $\mathrm{Cu}-\mathrm{Zr}-(\mathrm{Al}, \mathrm{Ti})$ bulk metallic glass composites, Scripta Mater. 60 (2009) 431-434.

[30] S. Pauly, G. Liu, G. Wang, J. Das, K.B. Kim, U. Kühn, D.H. Kim, J. Eckert, Modeling deformation behavior of $\mathrm{Cu}-\mathrm{Zr}-\mathrm{Al}$ bulk metallic glass matrix composites, Appl. Phys. Lett. 95 (2009) 101906.

[31] S. Pauly, G. Liu, G. Wang, U. Kühn, N. Mattern, J. Eckert, Microstructural heterogeneities governing the deformation of $\mathrm{Cu}_{47.5} \mathrm{Zr}_{47.5} \mathrm{Al}_{5}$ bulk metallic glass composites, Acta Mater. 57 (2009) 54455453.

[32] Y. Wu, Y. Xiao, G. Chen, C.T. Liu, Z. Lu, Bulk metallic glass composites with transformationmediated work-hardening and ductility, Adv. Mater. 22 (2010) 2770-2773.

[33] N.S. Barekar, S. Pauly, R.B. Kumar, U. Kühn, B.K. Dhindaw, J. Eckert, Structure-property relations in bulk metallic $\mathrm{Cu}-\mathrm{Zr}-\mathrm{Al}$ alloys, Mater. Sci. Eng. A 527 (2010), 5867-5872.

[34] A. Castellero, T. Baser, A.J. Das, P. Matteis, J. Eckert, L. Battezzati, M. Baricco, Role of crystalline precipitates on the mechanical properties of $\left(\mathrm{Cu}_{0.50} \mathrm{Zr}_{0.50}\right)_{100-\mathrm{x}} \mathrm{Al}_{\mathrm{x}}(\mathrm{x}=4,5,7)$ bulk metallic glasses, $\mathrm{J}$. Alloys Compd. 509 (2011), S99-S104.

[35] Y. Wu, H. Wang, H.H. Wu, Z.Y. Zhang, X.D. Hui, G.L. Chen, D. Ma, X.L. Wang, Z.P. Lu, Formation of $\mathrm{Cu}-\mathrm{Zr}-\mathrm{Al}$ bulk metallic glass composites with improved tensile properties, Acta Mater. 59 (2011), 2928-2936.

[36] Z.Q. Liu, R.L. Li, G. Su, W.H. Wang, H. Li, Y. Shi, M.J. Shi, X.K. Wu, G.J. Tao, Microstructural tailoring and improvement of mechanical properties in $\mathrm{CuZr}$-based bulk metallic glass composites, Acta Mater. 60 (2012), 3128-3139.

[37] K.K. Song, S. Pauly, B.A. Sun, Y. Zhang, J. Tan, U. Kühn, M. Stoica, J. Eckert, Formation of CuZr-Al-Er bulk metallic glass composites with enhanced deformability, Intermetallics 30 (2012) 132-138. 
[38] K.K. Song, S. Pauly, Y. Zhang, R. Li, S. Gorantla, N. Narayanan, U. Kühn, T. Gemming, J. Eckert, Triple yielding and deformation mechanisms in metastable $\mathrm{Cu}_{47.5} \mathrm{Zr}_{47.5} \mathrm{Al}_{5}$ composites, Acta Mater. 60 (2012) 6000-6012.

[39] C.N. Kuo, J.C. Huang, J.B. Li, J.S.C. Jang, C.H. Lin, T.G. Nieh, Effects of B2 precipitate size on transformation-induced plasticity of $\mathrm{Cu}-\mathrm{Zr}-\mathrm{Al}$ glassy alloys, J. Alloys Compd. 590 (2014) 453-458.

[40] F.F. Wu, K.C. Chan, S.S. Jiang, S.H. Chen, G. Wang, Bulk metallic glass composite with good tensile ductility, high strength and large elastic strain limit, Sci. Rep. 4 (2014) 5302.

[41] F.F. Wu, K.C. Chan, S.H. Chen, S.S. Jiang, G. Wang, ZrCu-based bulk metallic glass composites with large strain-hardening capability, Mater. Sci. Eng. A, 636 (2015) 502-506.

[42] A.V. Zhalko-titarenko, M.L. Yevlashina, V.N. Antonov, B.Yu. Yavorskii, Yu.N. Koval, G.S. First, Electronic and crystal structure of the $\mathrm{ZrCu}$ intermetallic compound close to the point of structural transformation, phys. stat. sol. (b) 184 (1994) 121-127.

[43] D. Schryvers, G.S. Firstov, J.W. Seo, J. Van Humbeeck, Yu.N. Koval, Unit cell determination in CuZr martensite by electron microscopy and X-ray diffraction, Scripta Mater. 6 (1997) 1119-1125.

[44] S. Pauly, J. Bednarčik, K. Jozef, K. Uta, J. Eckert, Plastically deformable Cu-Zr intermetallics, Scripta Mater. 63 (2010) 336-338.

[45] M.T. Hutchings, P. Withers, T. Holden, T. Lorentzen, Introduction to the Characterization of Residual Stress by Neutron Diffraction, CRC Press, Boca Raton, FL, 2005.

[46] W. Wu, K. An, L.K. Huang, S.Y. Lee, P.K. Liaw, Deformation dynamics study of a wrought magnesium alloy by real-time in situ neutron diffraction, Scripta Mater. 69 (2013) 358-361.

[47] E. Huang, D. Yu, J.W. Yeh, C. Lee, K. An, S.Y. Tu, A study of lattice elasticity from low entropy metals to medium and high entropy alloys, Scripta Mater. 101 (2015) 32-35.

[48] W. Wu, P.K. Liaw, K. An, Unraveling cyclic deformation mechanisms of a rolled magnesium alloy using in situ neutron diffraction, Acta Mater. 85 (2015) 343-353.

[49] D. Yu, K. An, Y. Chen, X. Chen, Revealing the cyclic hardening mechanism of an austenitic stainless steel by real-time in situ neutron diffraction, Scripta Mater. 89 (2014) 45-48. 
[50] O. Benafan, R.D. Noebe, II S.A. Padula, D.J. Gaydosh, B.A. Lerch, A. Garg, G.S. Bigelow, K. An, R. Vaidyanathan, Temperature dependent behavior of a polycrystalline NiTi shape memory alloy around the transformation regime, Scripta Mater. 68 (2013) 571-574.

[51] D. Yu, K. An, X. Chen, H. Bei, Phase-specific deformation behavior of a NiAl-Cr(Mo) lamellar composite under thermal and mechanical loads, J. Alloys Compd. 656 (2016) 481-490.

[52] D. Yu, H. Bei, Y. Chen, E.P. George, K. An, Phase-specific deformation behavior of a relatively tough NiAl-Cr(Mo) lamellar composite, Scripta Mater. $84-85$ (2014) 59-62.

[53] K. An, H.D. Skorpenske, A.D. Stoica, D. Ma, X.L. Wang, E. Cakmak, First in situ lattice strains measurements under load at VULCAN, Metall. Mater. Trans. A, 42 (2011) 95-99.

[54] Y. Chen, E. Rangasamy, C.R. Cruz, C.D. Liang, K. An, A study of suppressed formation of lowconductivity phases in doped $\mathrm{Li}_{7} \mathrm{La}_{3} \mathrm{Zr}_{2} \mathrm{O}_{12}$ garnets by in situ neutron diffraction, J. Mater. Chem. A 3 (2015) 22868-22876.

[55] Y. Chen, L. Yang, F. Ren, K. An, Visualizing the structural evolution of LSM/xYSZ composite cathodes for SOFC by in-situ neutron diffraction, Sci. Rep. 4 (2014) 5179.

[56] J.M. Liu, Preparation and properties of Zr-based bulk metallic glass composites (Doctor Dissertation), Shenyang University of Technology, China, 2010.

[57] K. An, VDRIVE-Data Reduction and Interactive Visualization Software for Event Mode Neutron Diffraction, ORNL Report, Oak Ridge National Laboratory, 2012, ORNL-TM-2012-621.

[58] A.C. Larson, R.B. Von Dreele, General Structure Analysis System. LANSCE, MS-H805, Los Alamos, New Mexico, 1994.

[59] P. Šittner, P. Lukáš, V. Novák, M.R. Daymond, G.M. Swallowe, In situ neutron diffraction studies of martensitic transformations in NiTi polycrystals under tension and compression stress, Mater. Sci. Eng. A 378 (2004) 97-104. 
[60] P. Sedmák, P. Šittner, J. Pilch, C. Curfs, Instability of cyclic superelastic deformation of NiTi investigated by synchrotron X-ray diffraction, Acta Mater. 94 (2015) 257-270.

[61] P. Sittner, P. Lukas, M.R. Daymond, V. Novak, G.M. Swallowe, Stress induced martensitic transformation in CuAlZnMn polycrystals investigated by in situ neutron diffraction, J. Phys. IV France11, 11 (2001) 159-166.

[62] P. Šittner, P. Lukáš, D. Neov, M.R. Daymond, V. Novák, G.M. Swallowe, Stress-induced martensitic transformation in $\mathrm{Cu}-\mathrm{Al}-\mathrm{Zn}-\mathrm{Mn}$ polycrystal investigated by two in-situ neutron diffraction techniques, Mater. Sci. Eng. A 324 (2002) 225-234.

[63] D. Neov, P. Sittner, M. Vrana, P. Mikula, In situ high-Resolution neutron diffraction study of stress induced martensitic transformations in CuAlZnMn shape memory alloy, Mater. Sci. Forum 347-349 (2000) 334-339.

[64] R. Vaydanathan, M.A.M. Bourke, D.C. Dunand, Phase fraction, texture and strain evolution in superelastic NiTi and NiTi-TiC composites investigated by neutron diffraction, Acta Mater. 47 (1999) $3353-3366$.

[65] G.S. Firstov, J. Van Humbeeck, Yu.N. Koval, Comparison of high temperature shape memory behavior for ZrCu-based, Ti-Ni-Zr and Ti-Ni-Hf alloys, Scripta Mater. 50 (2004), 243-248.

[66] J.W. Seo, D. Schryvers, TEM investigation of the microstructure and defects of CuZr martensite. Part I: morphology and twin systems, Acta Mater. 46 (1998) 1165-1 175.

[67] E. Bertrand, P. Castany, I. Pe'ron, T. Gloriant, Twinning system selection in a metastableb-titanium alloy by Schmid factor analysis, Scripta Mater. 64 (2011) 1110-1113.

[68] B. Clausen, T. Lorentzen, T. Leffers, Self-consistent modeling of the plastic deformation of F.C.C polycrystals and its implications for diffraction measurements of internal stresses, Acta Mater. 46 (1998) 3087-3098.

[69] D. Naito, S. Kubota, S. Harjo, Y. Tomota, In Situ Neutron Diffraction during Tension Compression Deformation for Nodular Graphite Cast Irons, ISIJ International 53 (2013) 1292-1294. 
[70] S. Morooka, Y. Tomota and T. Kamiyama, Heterogeneous deformation behavior studied by in situ neutron diffraction during tensile deformation for ferrite, martensite and pearlite steels, ISIJ International 48 (2008) 525-530. 


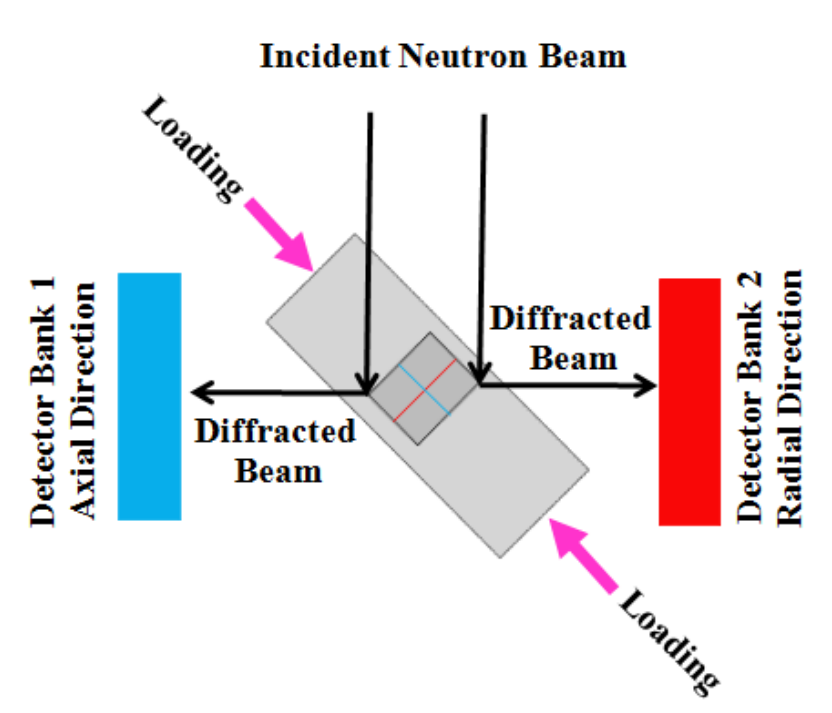

Figure 1. Schematic of the in-situ neutron diffraction setup at VULCAN, SNS, ORNL. The specimen was mounted horizontally in the VULCAN loadframe with the axial direction parallel to the loading direction (LD) and radial direction parallel to the transverse direction (TD), respectively. 


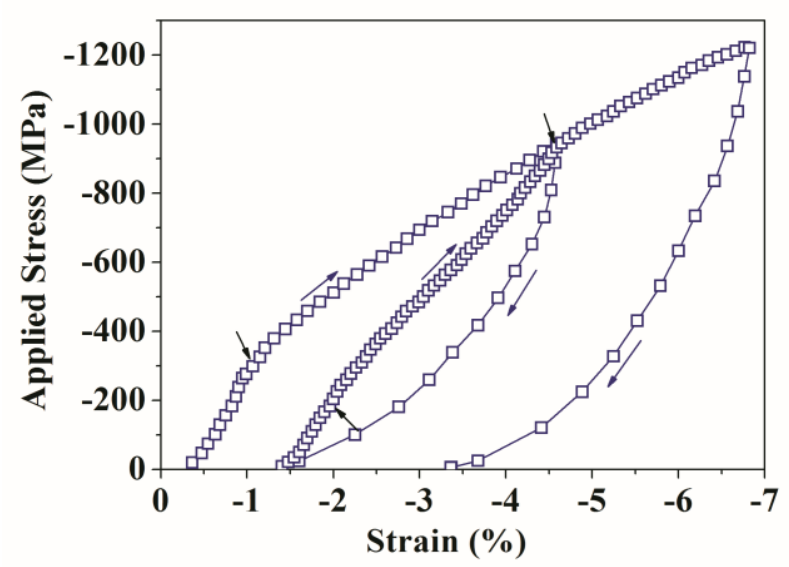

Figure 2. The measured compressive stress-strain curve for the two loading-unloading cycles throughout the in-situ neutron diffraction tests. 
(a)

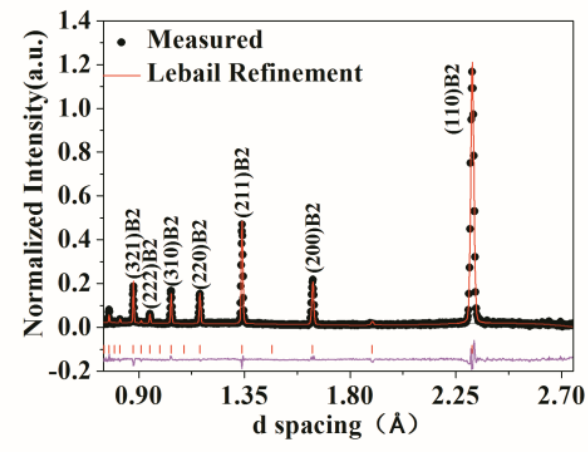

(c)

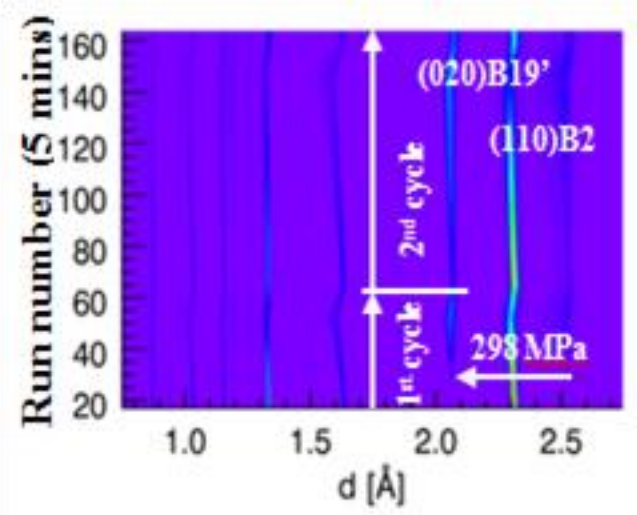

(b)

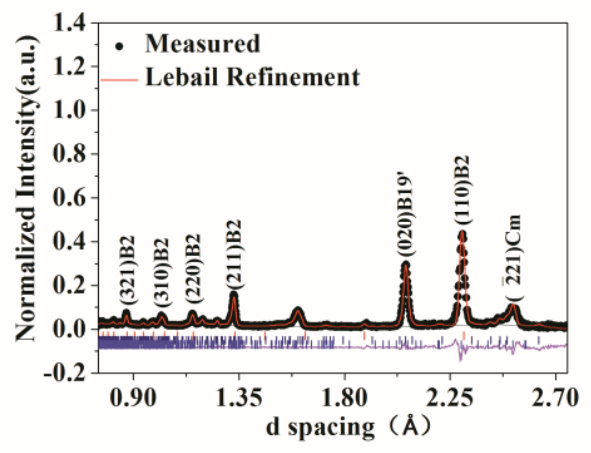

(d)

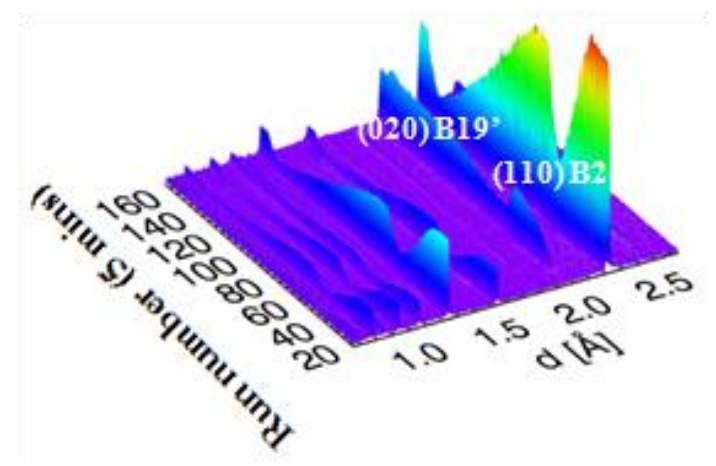

Figure 3. Lebail refinement results (a) before loading and (b) at the peak stress ( -941 MPa) in the $1^{\text {st }}$ cycle. The evolution of the whole neutron diffraction spectra over time in the loading direction in (c) two-dimensional (2-D) and (d) three dimensional (3-D) plots, respectively. 
(a)

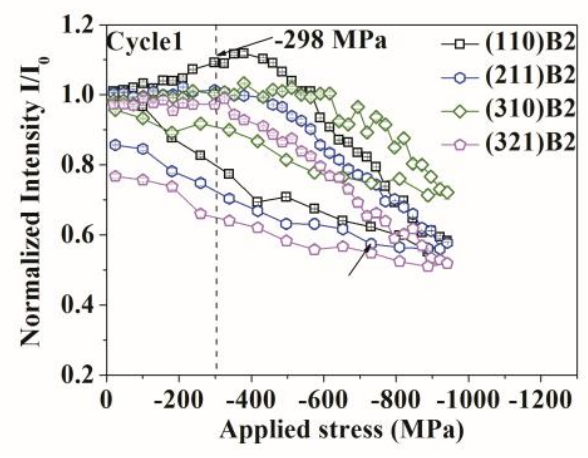

(c)
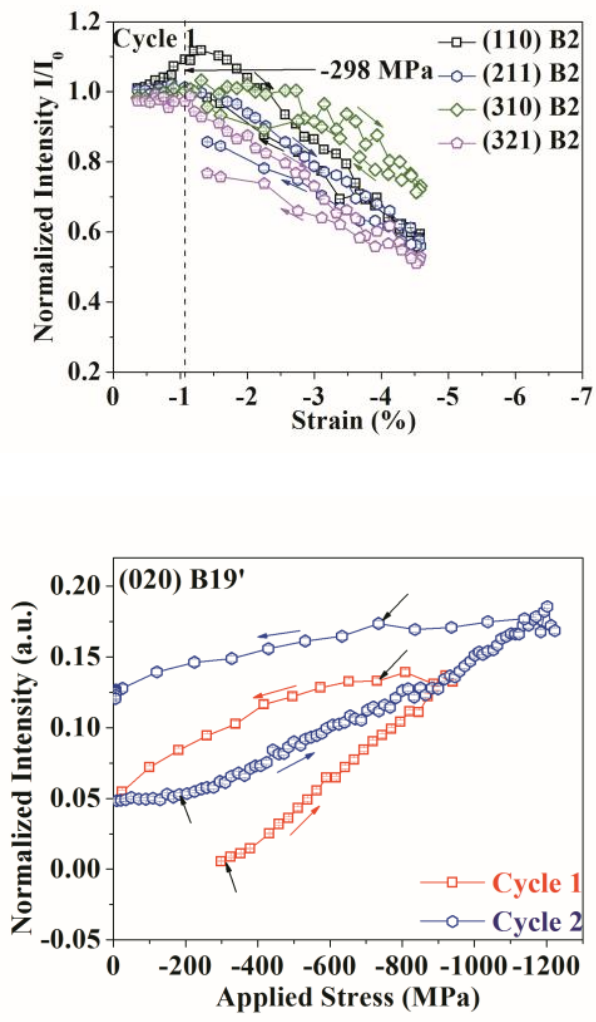

(e)

Figure 4. Responses of the normalized relative intensities of selected B2 peaks as as function of the applied stress in the loading direction for the (a) $1^{\text {st }}$ and (b) $2^{\text {nd }}$ cycles, respectively; Responses of the normalized relative intensities of selected B2 peaks as a function of the strain in the loading direction for the (c) $1^{\text {st }}$ and (d) $2^{\text {nd }}$ cycles, respectively; Responses of normalized intensities of B19' (020) peak as a function of (e) the applied stress and (f) the strain in the loading direction, respectively. 
(a)

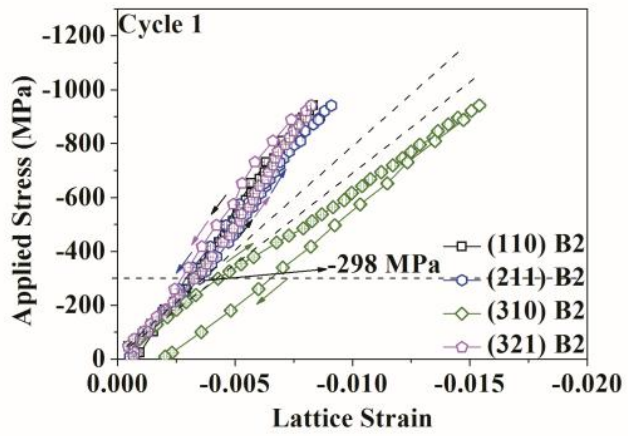

(c)

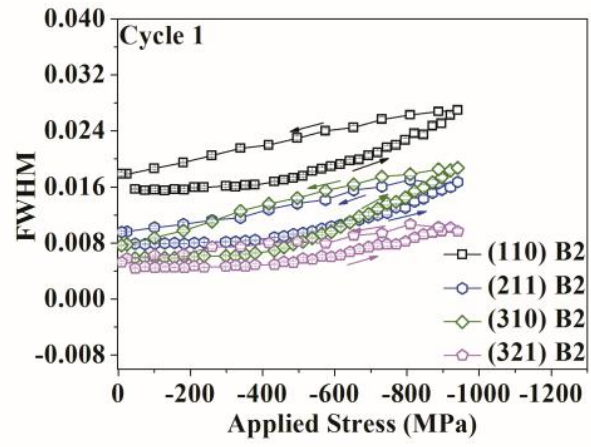

(e)

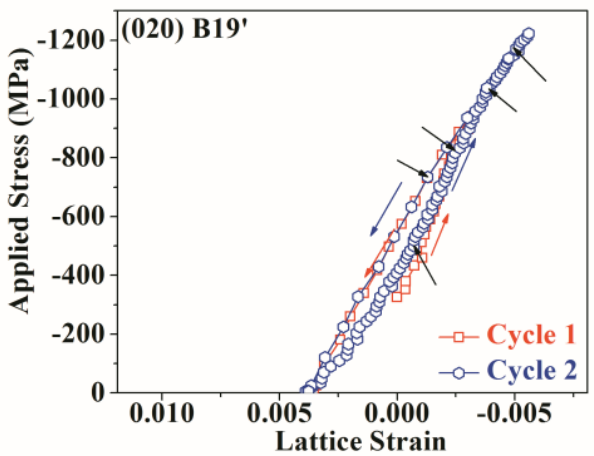

(f)

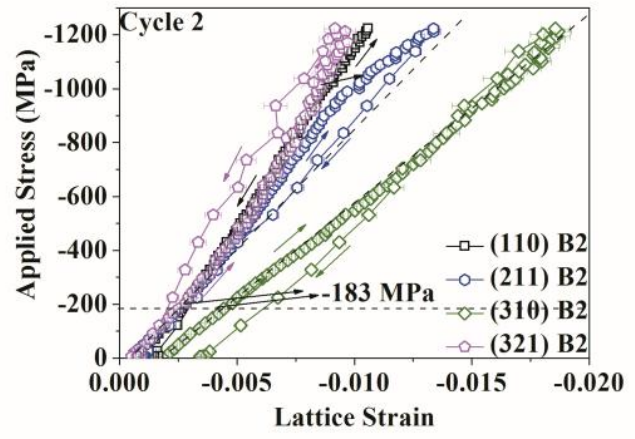

(d)
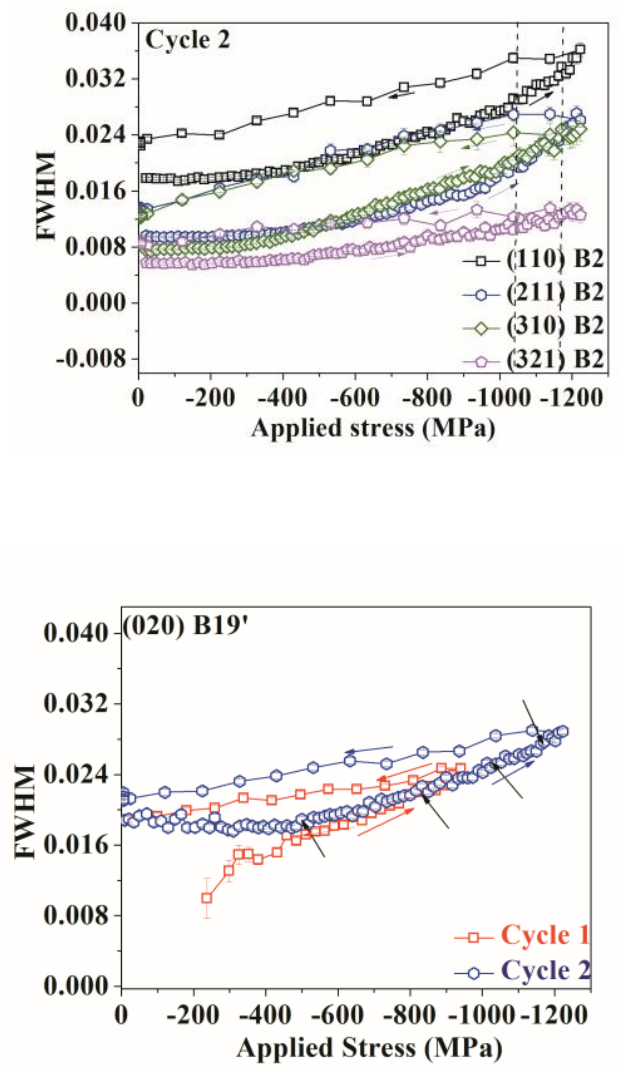

Figure 5. Responses of the lattice strain of the B2 phase to the applied stress in the loading direction for the (a) $1^{\text {st }}$ and (b) $2^{\text {nd }}$ cycles, respectively; Responses of the FWHM of the B2 phase as a function of the applied stress in the loading direction for the (c) $1^{\text {st }}$ and (d) $2^{\text {nd }}$ cycles, respectively; (e) Responses of lattice strain of B19' (020) grains to the applied stress in the $1^{\text {st }}$ and $2^{\text {nd }}$ cycles; (f) Response of the FWHM of B19' (020) grains as a function of the applied stress in the loading direction in the $1^{\text {st }}$ and $2^{\text {nd }}$ cycles. 


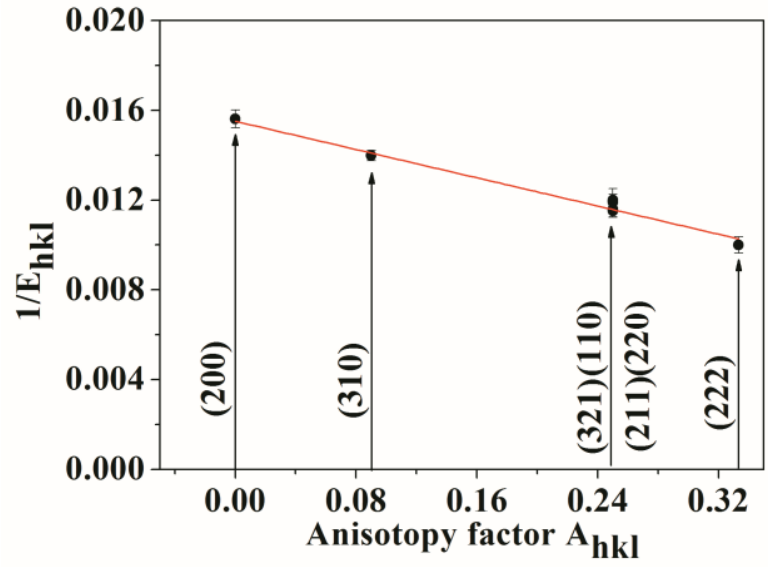

Figure $6.1 / \mathrm{E}_{\mathrm{hkl}}$ calculated from the lattice strain correspondences to the applied stress as a function of the orientation parameter $\mathrm{A}_{\mathrm{hkl}}$. 


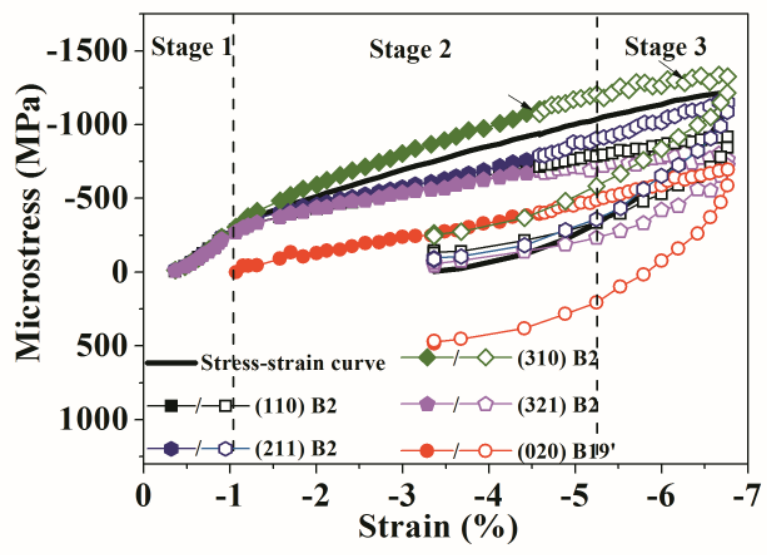

Figure 7. Part of the measured compressive stress-strain curve and part of the responses of microstress vs. strain for different $(h k l)$ planes of the austenite and B19' (020) martensite grains during the deformation process. Solid patterns represent the microstress variations in the $1^{\text {st }}$ cycle while hollow ones represent the microstress variations in the $2^{\text {nd }}$ cycle. 